\title{
Histidine $\mathrm{pK}_{\mathrm{a}}$ shifts and changes of tautomeric states induced by the binding of gallium-protoporphyrin IX in the hemophore Has $\mathrm{A}_{\mathrm{SM}}$
}

\author{
NICOLAS WOLFF, ${ }^{1}$ CLARISSE DENIAU, ${ }^{1}$ SYLVIE LÉTOFFÉ, ${ }^{2}$ CATHERINE SIMENEL, ${ }^{1}$ \\ VEENA KUMAR, ${ }^{3}$ IGOR STOJILJKOVIC,${ }^{3}$ CÉCILE WANDERSMAN, ${ }^{2}$ \\ MURIEL DELEPIERRE ${ }^{1}{ }^{\text {AND ANNE LECROISEY }}{ }^{1}$ \\ ${ }^{1}$ Unité de Résonance Magnétique Nucléaire des Biomolécules, CNRS URA 2185, Institut Pasteur, Paris, France \\ ${ }^{2}$ Unité des Membranes Bactériennes, CNRS URA 1300, Institut Pasteur, Paris, France \\ ${ }^{3}$ Department of Microbiology and Immunology, Emory University, Atlanta, Georgia 30322, USA
}

(Received August 21, 2001; Final Revision November 26, 2001; AccePted December 3, 2001)

\begin{abstract}
The Has $\mathrm{A}_{\mathrm{SM}}$ hemophore, secreted by Serratia marcescens, binds free or hemoprotein bound heme with high affinity and delivers it to a specific outer membrane receptor, HasR. In HasA $\mathrm{SM}_{\mathrm{SM}}$, heme is held by two loops and coordinated to iron by two residues, His 32 and Tyr 75. A third residue His 83 was shown recently to play a crucial role in heme ligation. To address the mechanistic issues of the heme capture and release processes, the histidine protonation states were studied in both apo- and holo-forms of Has $\mathrm{A}_{\mathrm{SM}}$ in solution. Holo-Has $\mathrm{A}_{\mathrm{SM}}$ was formed with gallium-protoporphyrin IX ( $\left.G a P P I X\right)$, giving rise to a diamagnetic protein. By use of heteronuclear correlation NMR spectroscopy, the imidazole side-chain ${ }^{15} \mathrm{~N}$ and ${ }^{1} \mathrm{H}$ resonances of the six $\mathrm{Has}_{\mathrm{SM}}$ histidines were assigned and their $\mathrm{pKa}$ values and predominant tautomeric states according to $\mathrm{pH}$ were determined. We show that protonation states of the heme pocket histidines can modulate the nucleophilic character of the two axial ligands and, consequently, control the heme binding. In particular, the essential role of the His 83 is emphasized according to its direct interaction with Tyr 75 .
\end{abstract}

Keywords: Histidine; tautomer; pKa; NMR; hemophore; gallium; protoporphyrin

Bacteria have developed various mechanisms for scavenging iron, thus allowing them to survive in iron-poor environments (Braun and Killmann 1999). One general mechanism involves the excretion of small inorganic iron chelators, termed siderophores, which display very high affinities for the metallic ion. The iron-loaded siderophores are recognized by specific outer membrane receptors that act in an energy-dependent way and allow the delivery of iron to the bacteria via a tonB-dependent process. Heme iron utilization is also widespread among bacterial pathogens. Various

Reprint requests to: Nicolas Wolff, Unité de RMN des Biomolécules, Département des Rétrovirus, Institut Pasteur, 28 rue du Docteur Roux, 75015, Paris; e-mail: wolff@ pasteur.fr; fax: 33-1-45-68-89-29.

Abbreviations: HasA, Haem acquisition system A; GaPPIX, galliumprotoporphyrin IX.

Article and publication are at http://www.proteinscience.org/cgi/doi/ 10.1110/ps.3630102. heme-containing compounds such as hemopexin, hemoglobin, haptoglobin-hemoglobin complex, or heme-loaded albumin are available within the host organism. One of these heme uptake systems is dependent on hemophores, which have a similar function to siderophores.

Hemophores (HasA) are small extracellular proteins secreted by an $\mathrm{ABC}$ transporter via their carboxy-terminal signal (Létoffé et al 1994a). They form an independent family of heme-binding proteins that are not homologous to any known proteins. The role of the hemophores is to bind free or hemoprotein-bound heme and to deliver it to a specific outer membrane receptor, HasR (Ghigo et al. 1997). The Serratia marcescens Has $_{\mathrm{SM}}$ hemophore is a monomer (19 $\mathrm{kD}$ ) that binds $\mathrm{b}$ heme with a stoichiometry of one and a very high affinity $\left(\mathrm{K}_{\mathrm{a}}>10^{8} \mathrm{M}^{-1}\right)$ (Izadi et al. 1997). The crystal structure of the holo-Has $\mathrm{A}_{\mathrm{SM}}$ contains an original $\alpha / \beta$ fold and an unusual pattern of $b$ heme ligation (Arnoux 
et al. 1999). Heme, which is highly exposed to solvents, is held by two loops and coordinated to iron by two residues, His 32 and Tyr 75. This histidine/tyrosine ligand pair of $b$ heme iron has only been observed in alkaline ferric Chlamydomonas chloroplast hemoglobin (Das et al. 1999) and in a few mutated proteins (Nagai et al. 1989; Maurus et al. 1994). A third residue, His 83, which forms a hydrogen bond with Tyr 75, was shown recently to play a crucial role in heme ligation in an extensive study of Has $\mathrm{A}_{\mathrm{SM}}$ mutant proteins (Létoffé et al. 2001).

Histidine residues often serve critical functional roles, acting either as nucleophiles or as electrophiles. The $\mathrm{pKa}$ of free imidazole rings is close to the physiological $\mathrm{pH}$, allowing the ionization state of this side chain to be modulated readily by its environment within the protein (Nozaki and Tanford 1967; Tanokura 1983). The protonation state and hydrogen bonding of the His 32 and His 83 heme pocket histidines residues in Has $\mathrm{A}_{\mathrm{SM}}$ might be essential for heme capture and release processes. Therefore, the ${ }^{15} \mathrm{~N}$ and ${ }^{1} \mathrm{H}$ histidine imidazole signals in both apo- and holo-Has $\mathrm{A}_{\mathrm{SM}}$ were followed with ${ }^{15} \mathrm{~N}$ heteronuclear correlation NMR spectroscopy as a function of $\mathrm{pH}$ to determine their $\mathrm{pKa}$ values and their protonation state.

Heme iron within the heme-Has $\mathrm{A}_{\mathrm{SM}}$ complex is in a low spin ferric state and is, therefore, paramagnetic (Izadi et al. 1997). Moreover, its very low redox potential value $(-550$ $\mathrm{mV}$ vs. standard hydrogen electrode) precludes the reduction of the holo-protein in aerobic conditions. We thus chose a diamagnetic non-iron metalloporphyrin to form the holoprotein, the gallium-protoporphyrin IX (GaPPIX). This prevented any resonance shifts and relaxation effects induced by paramagnetism in the holo-protein and allowed us to observe and to compare the heme binding pocket histidines in apo- and holo-Has $\mathrm{A}_{\mathrm{SM}}$ directly.

In this study, we measured the affinity constant of Has $_{\mathrm{SM}}$ for GaPPIX. We assigned the imidazole side-chain ${ }^{15} \mathrm{~N}$ and ${ }^{1} \mathrm{H}$ resonances, and determined the $\mathrm{pKa}$ values and the predominant tautomeric state according to the $\mathrm{pH}$ of all six histidines of $\mathrm{Has}_{\mathrm{SM}}$ in both its apo- and holo-forms. Protonation features of the histidines are discussed. Further insights into the structural factors of the heme pocket in both the apo- and holo-Has $\mathrm{A}_{\mathrm{SM}}$ proteins are given; these allow us to address the mechanistic issues of the heme binding and release processes.

\section{Results and Discussion}

\section{General features}

Most of the protons attached directly to imidazole ring nitrogen atoms could not be observed by NMR because they exchange with water too quickly. In contrast, the nonexchangeable $\mathrm{H} \delta 2$ and $\mathrm{H} \varepsilon 1$ protons, which are linked to the nitrogens via weak two- and three-bond couplings, could be detected in ${ }^{1} \mathrm{H}\left\{{ }^{15} \mathrm{~N}\right\}$ SBC and ${ }^{1} \mathrm{H}\left\{{ }^{15} \mathrm{~N}\right\} \mathrm{MBC}$ spectra. The cross-peak pattern enables the unambiguous assignment of the $\mathrm{N} \delta 1$ and $\mathrm{N} \varepsilon 2$ nitrogen as well as of the $\mathrm{H} \delta 1$ and $\mathrm{H} \varepsilon 2$ proton frequencies. Cross-peak intensities reflect the magnitude of the coupling constants between correlated ${ }^{1} \mathrm{H}$ and ${ }^{15} \mathrm{~N}$ atoms. The magnitude of the three-bond ${ }^{3} \mathrm{JN} \delta 1-\mathrm{H} \delta 2$ coupling constant is lower than that of the ${ }^{2} \mathrm{JNH}$ coupling constants in both the protonated and the neutral histidine ring. Thus, the ${ }^{3} \mathrm{JN} \delta 1-\mathrm{H} \delta 2$ coupling produces only weak or even unobservable cross-peak (Blomberg et al. 1977).

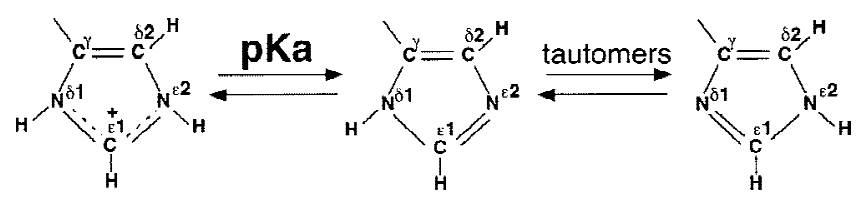

Specific assignment of the ${ }^{15} \mathrm{~N}$ and ${ }^{1} \mathrm{H}$ resonances of the six histidine rings of $\mathrm{Has}_{\mathrm{SM}}$ were determined from ${ }^{1} \mathrm{H}\left\{{ }^{15} \mathrm{~N}\right\} \mathrm{SBC}$ and ${ }^{1} \mathrm{H}\left\{{ }^{15} \mathrm{~N}\right\} \mathrm{MBC}$ cross peak patterns (Table 1). Spin systems were assigned to His 32 and His 83 in apo-Has $_{\mathrm{SM}}$ and in GaPPIX-Has $\mathrm{A}_{\mathrm{SM}}$ by comparing the spectra recorded for the wild-type protein and for the His32Ala and His83Ala mutant proteins. The remaining histidines (His 17, His 128, His 133, and His 179) in apoHas $_{\text {SM }}$ were identified from the correlations observed in ${ }^{13} \mathrm{C}$ NOESY-HSQC spectra between histidines $\delta$ and $\beta$ protons. These four histidines in GaPPIX-Has $\mathrm{A}_{\mathrm{SM}}$ were assigned from the similarities between the apo-Has $\mathrm{A}_{\mathrm{SM}}$ and the complexed HasA spectra. The protonation states of individual nitrogens were then inferred from ${ }^{15} \mathrm{~N}$ chemical shifts; in a positively charged ring, both protonated and partially charged nitrogens resonate at $176.5 \mathrm{ppm}($ type- $\alpha+)$ and in a neutral ring, an unprotonated nitrogen typically resonates at $249.5 \mathrm{ppm}$ (type- $\beta$ ), whereas a protonated nitrogen resonates at $167.5 \mathrm{ppm}$ (type- $\alpha$ ), that is at $82 \mathrm{ppm}$ upfield. Intermediate values are indicative of a fast exchange between the two tautomers and the $\alpha$-type or $\beta$-type character of a nitrogen can be estimated from the differences between the observed and the theoretical chemical shift values (Van Dijk et al 1992; Pelton et al. 1993; Bhattacharya et al. 1997). An imidazole ring with an equal population of ${ }^{15} \mathrm{~N} \varepsilon$ and ${ }^{15} \mathrm{~N} \delta$-protonated neutral tautomers would yield an average chemical shift of $210 \mathrm{ppm}$. However, the local environment and the hydrogen bonding of the histidine may induce compensatory shifts. Thus, a type- $\beta$ nitrogen moves upfield (in the direction of the protonation) when behaving as an acceptor in a hydrogen bond, whereas a type $\alpha$ or $\alpha+$ nitrogen moves downfield (in the direction of deprotonation) when behaving as a donor. The magnitude of these shifts can reach $10 \mathrm{ppm}$. Hence, information on the tautomeric equilibrium and the hydrogen bond status from the nitrogen chemical shifts must be collected carefully. 
Table 1. Observed ${ }^{15} \mathrm{~N}$ (left) and ${ }^{1} \mathrm{H}$ (right) chemical shifts (ppm) of Has $A_{S M}$ in apo- and holo-forms

\begin{tabular}{|c|c|c|c|c|c|c|c|c|c|c|c|c|}
\hline \multirow[b]{2}{*}{ Residue } & \multirow[b]{2}{*}{ Atom } & \multicolumn{3}{|c|}{ apo-HasA $\mathrm{S}_{\mathrm{SM}}$} & \multicolumn{3}{|c|}{ holo-Has $\mathrm{A}_{\mathrm{SM}}$} & \multirow[b]{2}{*}{ Atom } & \multicolumn{2}{|c|}{ apo-HasA $\mathrm{SM}_{\mathrm{SM}}$} & \multicolumn{2}{|c|}{ holo-Has $\mathrm{A}_{\mathrm{SM}}$} \\
\hline & & $\delta_{\mathrm{N}}^{\mathrm{AH}^{+}}$ & $\delta_{\mathrm{N}}^{\mathrm{A}}$ & $\left|\Delta_{N}^{\mathrm{A}}\right|$ & $\delta_{\mathrm{N}}^{\mathrm{AH}^{+}}$ & $\delta_{\mathrm{N}}^{\mathrm{A}}$ & $\left|\Delta_{N}^{\mathrm{A}}\right|$ & & $\delta_{\mathrm{H}}^{\mathrm{AH}^{+}}$ & $\delta_{\mathrm{H}}^{\mathrm{A}}$ & $\delta_{\mathrm{H}}^{\mathrm{AH}^{+}}$ & $\delta_{\mathrm{H}}^{\mathrm{A}}$ \\
\hline \multirow[t]{2}{*}{ His 17} & $\mathrm{~N}^{\delta 1}$ & 183.4 & nd & \multirow{2}{*}{ - } & 184.1 & 172.2 & \multirow{2}{*}{71} & $\mathrm{H}^{\delta 2}$ & 7.32 & nd & 7.34 & 6.85 \\
\hline & $\mathrm{N}^{\varepsilon 2}$ & 171.0 & nd & & 170.3 & 243.2 & & $\mathrm{H}^{\varepsilon 1}$ & 8.51 & nd & 8.52 & 7.63 \\
\hline \multirow[t]{2}{*}{ His 32} & $\mathrm{~N}^{\delta 1}$ & 173.6 & 254.4 & \multirow{2}{*}{78.3} & 164.6 & 163.4 & \multirow{2}{*}{70.3} & $\mathrm{H}^{\delta 2}$ & 6.61 & 6.43 & 0.40 & 0.40 \\
\hline & $\mathrm{N}^{\varepsilon 2}$ & 180.7 & 167.1 & & 229.0 & 233.7 & & $\mathrm{H}^{\varepsilon 1}$ & 8.79 & 7.76 & 1.31 & 1.21 \\
\hline \multirow[t]{2}{*}{ His 83} & $\mathrm{~N}^{\delta 1}$ & nd & 227.3 & \multirow{2}{*}{59.4} & 185.2 & 165.4 & \multirow{2}{*}{76.9} & $\mathrm{H}^{\delta 2}$ & 7.36 & 7.05 & 6.89 & 6.15 \\
\hline & $\mathrm{N}^{\varepsilon 2}$ & 172.2 & 167.9 & & 168.3 & 242.3 & & $\mathrm{H}^{\varepsilon 1}$ & 8.54 & 7.59 & 4.71 & 4.93 \\
\hline \multirow[t]{2}{*}{ His 128} & $\mathrm{~N}^{\delta 1}$ & 175.1 & 231.5 & \multirow{2}{*}{67.1} & 175.1 & 244.1 & \multirow{2}{*}{79.3} & $\mathrm{H}^{\delta 2}$ & 6.63 & 6.35 & $6.60 / 6.47$ & $6.33 / 6.2$ \\
\hline & $\mathrm{N}^{\varepsilon 2}$ & 169.4 & 164.4 & & 170.1 & 164.8 & & $\mathrm{H}^{\varepsilon 1}$ & 8.66 & 7.62 & 9.04 & 7.95 \\
\hline \multirow[t]{2}{*}{ His 133} & $\mathrm{~N}^{\delta 1}$ & 253.5 & 253.5 & \multirow[b]{2}{*}{92} & 257.2 & 256.5 & \multirow{2}{*}{95.5} & $\mathrm{H}^{\delta 2}$ & 6.81 & 6.74 & 7.20 & 7.09 \\
\hline & $\mathrm{N}^{\varepsilon 2}$ & 162.3 & 161.5 & & 162.6 & 161 & & $\mathrm{H}^{\varepsilon 1}$ & 7.40 & 7.46 & 8.83 & 8.95 \\
\hline \multirow[t]{2}{*}{ His 179} & $\mathrm{~N}^{\delta 1}$ & 176.6 & 245.1 & \multirow{2}{*}{63.8} & 175.2 & 220.6 & \multirow{2}{*}{31.7} & $\mathrm{H}^{\delta 2}$ & 7.33 & 6.97 & 7.28 & 6.92 \\
\hline & $\mathrm{N}^{\varepsilon 2}$ & 172.6 & 181.3 & & 172.1 & 188.9 & & $\mathrm{H}^{\varepsilon 1}$ & 8.64 & 7.64 & 8.61 & 7.67 \\
\hline
\end{tabular}

The ${ }^{15} \mathrm{~N}$ and ${ }^{1} \mathrm{H}$ chemical shifts of the protonated and deprotonated states were obtained from the experimental data by a least-square fitting procedure as described in the text. As only partial curve titration could be obtained for His 83 nitrogens, their chemical shifts are reported for the lowest and highest $\mathrm{pH}$ at which peaks were observed in the heteronuclear correlation NMR spectra. The same procedure was applied for His 133 in both Has $\mathrm{A}_{\mathrm{SM}}$ apo- and holofoms and for His 32 in the Has $\mathrm{A}_{\mathrm{SM}}$ holo-form, as their nitrogens and protons did not titrate within the pH range studied.

Note that free histidine forms a mixture with appoximately a $4: 1$ preference for $\mathrm{N} \varepsilon 2 \mathrm{H}$ protonation and displays an $\sim 50$ ppm difference between its two imidazole nitrogen chemical shifts. $\mathrm{N} \varepsilon 2$ and $\mathrm{N} \delta 1$ atoms have distinct microscopic $\mathrm{pKa}$; the $\mathrm{N} \varepsilon 2 \mathrm{pKa}$ being slightly more basic than the $\mathrm{N} \delta 1$ pKa (Tanokura 1983).

For titration with protoporphyrin, gallium seemed to be an apropriate substitute for ferric iron because $\mathrm{Ga}^{3+}$ and $\mathrm{Fe}^{3+}$ have a similar charge, atomic radius $(0.62 \AA$ vs. 0.65 $\AA$ ) and coordination preferences (Martin 1988). $\mathrm{Ga}^{3+}$ is the only biochemically accessible redox state. Also, it has already been shown that enzymes or proteins that use heme as a cofactor can incorporate GaPPIX into their catalytic centres (Stojilkovic et al. 1999). Absorption spectoscopy showed that wild-type HasA binds GaPPIX with a stoichiometry of one and with a Ka value of 5.3( \pm 1.3$) \cdot 10^{7} \mathrm{M}^{-1}$. Moreover, when Has $\mathrm{A}_{\mathrm{SM}}$ is complexed with gallium, it is able to interact with its receptor, HasR, and can deliver GaPPIX to the cell (S. Létoffé and C. Wandersman, unpubl.). Lastly, we recently determined the backbone assign-

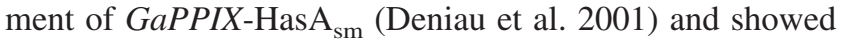
that the secondary structures and the overall fold of the protein are similar with those of heme-HasA $\mathrm{sm}_{\mathrm{sm}}$.

The NMR spectra of GaPPIX-Has $\mathrm{A}_{\mathrm{SM}}$ revealed a splitting of the heme pocket histidine peaks, with largest differences in chemical shift of $0.15 \mathrm{ppm}$ in proton and $1 \mathrm{ppm}$ in nitrogen. Two protein forms, in which the orientation of the heme differs by a $180^{\circ}$ rotation around the $\alpha \gamma$ meso axis, have been found in most myoglobins, hemoglobins, and other b-type hemoproteins (Yamamoto et al. 1998). The functional consequence of the two forms has not yet been established. The X-ray crystal structure of $\mathrm{HasA}_{\mathrm{SM}}$ at a resolution of $1.77 \AA$ also showed that heme could take these two orientations in the crystal, with a ratio of about 1:1
(Arnoux et al. 2000). These data and the fact that the relative intensities of each couple of peaks were similar $(\sim 40$ : 60 ) for the heme pocket histidines, suggest that GaPPIX can also take two orientations in slow exchange on the NMR chemical shift time scale. The chemical environment of the protein atoms in the binding site (electronic structure of the pyrroles, metal-centered dipolar magnetic field, propionate side chains conformation) would only be influenced slightly by the heme rotation, explaining the low differences in chemical shifts observed between the two sets of peaks.

\section{His 32}

According to the X-ray structure, His 32 was almost completely buried in the holo-form of the protein. Its $\mathrm{N} \varepsilon 2$ was coordinated to the heme iron and its $\mathrm{N} \delta 1$ formed a tight hydrogen bond with the backbone carbonyl group of Asn 41.

The $\mathrm{pKa}$ of His 32 in apo-Has $\mathrm{A}_{\mathrm{SM}}$ was neutral, slightly higher than the value of $\sim 6.8$ found for a histidine residue in an unstructured peptide and consistent with a rather large accessibility to solvents (Table 2). The cross peak pattern observed in the ${ }^{1} \mathrm{H}-{ }^{15} \mathrm{~N}$ NMR spectra at basic $\mathrm{pH}$ showed three connectivities, indicating the formation of the $\mathrm{N} \varepsilon 2 \mathrm{H}$ tautomer. The missing N $\delta 1-\mathrm{H} \delta 2$ cross peak appears in the protonated form of the residue, when the $\mathrm{pH}$ is lowered. The chemical shift values of type $\alpha$ and type $\beta$ nitrogens were similar to the values for pure $\alpha$ and $\beta$ types, with a difference of $78 \mathrm{ppm}$. These data show that the $\mathrm{N} \varepsilon 2 \mathrm{H}$ tautomeric form is highly predominant and that it precludes in apoHasA $_{\mathrm{SM}}$ the Asn $41 \mathrm{CO}-\mathrm{His} 32 \mathrm{~N} \delta 1$ interaction observed in the holo-Has $\mathrm{A}_{\mathrm{SM}}$ structure.

Spectra of GaPPIX-Has $\mathrm{A}_{\mathrm{SM}}$ presented connectivities that are consistent with the formation of the His $32 \mathrm{~N} \delta 1 \mathrm{H}$ tau- 
Table 2. Histidine pKa values in wild-type apo-and holo-Has $A_{S M}$ and in Tyr75Ala mutant apo-HasA $A_{S M}$

\begin{tabular}{lcccc}
\hline & \multicolumn{3}{c}{ pKa } & $\begin{array}{c}\text { Accessible } \\
\text { surface } \\
\left(\AA^{2}\right)\end{array}$ \\
\cline { 2 - 4 } Residue & apo-HasA & GaPPIX-HasA & apo-Tyr75Ala & $84 / 84$ \\
\hline His 17 & $>8.1$ & 8.7 & $>8.5$ & $7 / 43$ \\
His 32 & 7.3 & $<4.8$ & 7.5 & $25 / 81$ \\
His 83 & 5.6 & 9.7 & 7.0 & $92 / 106$ \\
His 128 & 7.1 & 7.4 & 7.2 & $12 / 27$ \\
His 133 & $<4.6$ & $<4.8$ & $<5.7$ & nd \\
His 179 & 7.1 & 7.4 & 7.2 &
\end{tabular}

The $\mathrm{pKa}$ values were determined from fitting the $\mathrm{pH}$ titration curves of ${ }^{15} \mathrm{~N}$ and the ${ }^{1} \mathrm{H}$ chemical shifts to a modified Henderson-Hasselbalch equation by nonlinear least-squares analysis.

The accessible surface $\left(\AA^{2}\right)$ were calculated with and without (./.) b heme in the HasA $\mathrm{SM}_{\mathrm{SM}} \mathrm{X}$-ray structure.

tomer. Thus, coordination to gallium occurs through the $\mathrm{N} \varepsilon$ atom as does coordination to iron. His 32 did not titrate over the $\mathrm{pH}$ range studied. Its $\mathrm{pKa}$ value, below 4.8 , indicates that protonation of $\mathrm{N} \varepsilon$ and disruption of the ligation to gallium requires a very low $\mathrm{pH}$. A slight chemical shift deviation was observed for $\mathrm{H} \varepsilon 1$ and $\mathrm{N} \varepsilon 2$ when the $\mathrm{pH}$ was above 9. As seen below, His 83 has a basic pKa of 9.7 in GaPPIX-Has $\mathrm{A}_{\mathrm{SM}}$, and this deviation probably results in a secondary effect due to His 83 titration. His $32 \mathrm{H} \varepsilon 1$ and

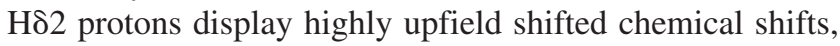
at 1.21 and $0.40 \mathrm{ppm}$, respectively (Fig. 1). Similar shifts caused by the protoporphyrin ring current have also been observed for the imidazole protons of iron coordinated histidines in other diamagnetic hemoproteins as follows: reduced cytochrome b5, hemoglobin-CO, cytochrome cd1 nitrite reductase (Guiles et al. 1990; Alam et al. 1998;
Steensma et al. 2001). Although nitrogen chemical shifts are perturbed to a lesser extent than proton chemical shifts, they may also be affected by the protoporphyrin ring current. Thus, this would preclude the identification of hydrogen bonds from their sole chemical shifts values; an upfield shift of 4.5 ppm caused by heme ring current was thus observed in ferrocytochrome c 2 of Rodospirillum rubrum for the N $\delta 1$ of the coordinated histidine ( $\mathrm{Yu}$ and Smith 1990). Therefore, the His $32 \mathrm{~N} \delta 1$ chemical shift value did not allow us to determine unambiguously the hydrogen bonding of His 32 to Asn 41, although the bond between His $32 \mathrm{H \delta} 1$ and the backbone carbonyl of Asn 41 is likely to exist in $\mathrm{GaPPIX}$-Has $_{\mathrm{SM}}$ as in the heme-Has $\mathrm{A}_{\mathrm{SM}}$ complex. In other hemoproteins with an iron coordinated histidine, a hydrogen bond was also observed between the axial histidine $\mathrm{H} \delta 1$ and a carbonyl group of the backbone or an amino acid side chain of the protein (Rousseau and Rousseau 1992). This bond makes the histidine more anionic and therefore reinforces the strength of the coordination.

\section{His 83}

The structure of holo-Has $\mathrm{A}_{\mathrm{SM}}$ showed that His 83 is located at the edge of the heme pocket, exposed to solvent, and that it forms a hydrogen bond via its $\mathrm{N} \delta 1$ with the hydroxyl group of Tyr 75. In most apo-Has $\mathrm{A}_{\mathrm{SM}}$ spectra, the His 83 resonances are weak or undetectable and only partial ${ }^{15} \mathrm{~N}$ and ${ }^{1} \mathrm{H}$ titration curves could be obtained. As the $\mathrm{J}_{\mathrm{NH}}$ coupling constant values only varied slightly with the protonation state of the imidazole ring, the cross-peaks for His 83 probably disappear due to line broadening of the ${ }^{1} \mathrm{H}$ and/or ${ }^{15} \mathrm{~N}$ signals as a result of intermediate exchange of tau-
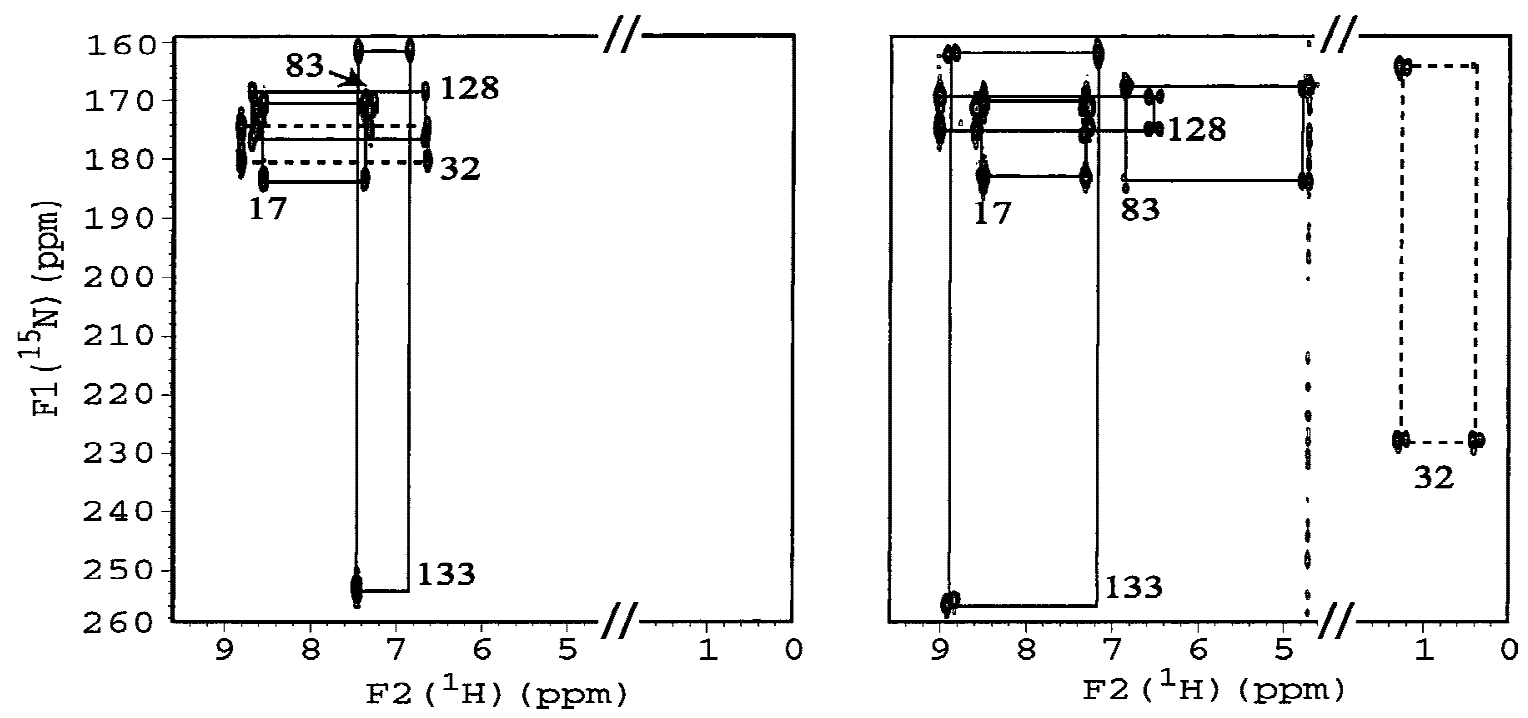

Fig. 1. Portions of ${ }^{1} \mathrm{H}\left\{{ }^{15} \mathrm{~N}\right\} \mathrm{MBC}$ spectra of uniformly ${ }^{15} \mathrm{~N}$ labeled HasA in the apo-form (left) and in the holo-form (right) in $20 \mathrm{mM}$ sodium phosphate buffer ( $\mathrm{pH}$ 5.6) and $30^{\circ} \mathrm{C}$. Only His 17, His 32, His 83, His 128, and His 133 cross peak patterns are indicated. 
tomerization (Blomberg et al. 1977). The magnitude of the rate constant in the tautomeric equilibrium is critical for the spectral appearance of the resonance. The His 83 cross-peak pattern indicated the formation of a predominant $\mathrm{N} \varepsilon 2 \mathrm{H}$ tautomeric form. The nitrogen chemical shift separation, 59 ppm, was low compared with that of pure $\alpha$ and $\beta$ types. However, as nitrogen chemical shifts could not be obtained over the entire $\mathrm{pH}$ range (Fig. 2), it is therefore difficult to comment on $\mathrm{N} \delta 1 \mathrm{H}-\mathrm{N} \varepsilon 2 \mathrm{H}$ tautomerization. The low value

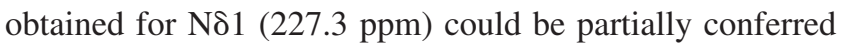
to the hydrogen bonding between His 83, the hydrogen acceptor via its $\mathrm{N} \delta 1$, and Tyr 75 acting as a hydrogen donor through its hydroxyl proton $\mathrm{H} \eta$. This hydrogen bond that stabilizes the neutral form of His 83 may account for the low $\mathrm{pKa}$ of this residue (5.6).

To investigate His 83-Tyr 75 hydrogen bonding, we followed the titration of the histidines as a function of $\mathrm{pH}$ in the Tyr75Ala mutant apo-protein. The only histidine that was significantly affected by the loss of the tyrosine was His 83. Its pKa increased by 1.4 unit (7.0), which is close to the value for a free histidine. This strongly suggests the direct influence of Tyr 75 on its protonation state (Table 2). The $\mathrm{N} \varepsilon 2 \mathrm{H}$ tautomer was predominant but, as in the wild-type protein, the N $\delta 1$ chemical shift limits could not be reached. The highest value obtained, $236 \mathrm{ppm}$, did not allow to state that $\mathrm{H} 83$ is involved in a hydrogen bond.

GaPPIX binding highly affected the cross peak pattern and the $\mathrm{pKa}$ value of His 83. Connectivities and nitrogen resonance separation in $G a P P I X-H a s A_{\mathrm{SM}}$ spectra indicate the formation of the $\mathrm{N} \delta 1 \mathrm{H}$ tautomer instead of $\mathrm{N} \varepsilon 2 \mathrm{H}$ in the apo-form of the protein. $\mathrm{H} \varepsilon 1$ and $\mathrm{H} \delta 2$ protons are upfield shifted (4.93 and $6.15 \mathrm{ppm}$, respectively), reflecting the protoporphyrin ring current effect, although this was less pronounced than for His 32. The pKa became extremely basic (9.7), thus, His 83 remained in a protonated state over a large $\mathrm{pH}$ range. The proximity of the protoporphyrin pre- vented us from determining the hydrogen bonding of the imidazole from its $\mathrm{N} \delta 1$ and $\mathrm{N} \varepsilon 2$ chemical shifts. However, the very high and unusual pKa of His 83 is probably due to a strong interaction between the proton $\mathrm{N} \delta 1 \mathrm{H}$ and the deprotonated phenolic oxygen, $\mathrm{O} \eta$. The low redox potential of holo-Has $\mathrm{A}_{\mathrm{SM}}(-540 \mathrm{mV})$ and the ferric state of the iron (Izadi et al. 1997) were consistent with localized Oๆ negative charge favoring the binding to the metallic ion.

We observed two sets of peaks for His 83 in the GaPPIXTyr75Ala mutant protein. The imidazole proton chemical shifts in both sets were shifted compared with those of the apo-protein. This is in agreement with the proximity of the protoporphyrin. At neutral $\mathrm{pH}$, one set was consistent with a neutral imidazole ring, and the other with a protonated one. All other histidines behaved in the same manner in the GaPPIX-Tyr75Ala protein and in the GaPPIX-wild-type protein. A recent study on Has $\mathrm{A}_{\mathrm{SM}}$ mutant proteins (Létoffé et al. 2001) found that His 83 appears to be an alternative iron coordination residue. The neutral form of His $83 \mathrm{ob}-$ served at neutral $\mathrm{pH}$ might correspond to an axial ligand of the metal via its $\mathrm{N} \delta 1$ in absence of the natural ligand, Tyr 75. However, coordination of histidines to $b$ heme iron in hemoproteins were thought to occur through their $\mathrm{N} \varepsilon 2$. Therefore, we have to confirm this type of N $\delta 1$ ligation. The protonated form may correspond to Has $\mathrm{A}_{\mathrm{SM}}$ molecules with just one remaining axial ligand (His 32 ).

\section{His 128 and His 133}

As shown by the crystal structure of holo-Has $\mathrm{A}_{\mathrm{SM}}$, His 128 and His 133 are located at the bottom of the heme pocket. His 128 is very accessible to solvent and its $\mathrm{N} \varepsilon 2$ forms a hydrogen bond with the backbone carbonyl group of Ala 82 . His 133 is completely buried and its $\mathrm{N} \varepsilon 2$ forms a hydrogen bond with the backbone carbonyl group of His 83 . These
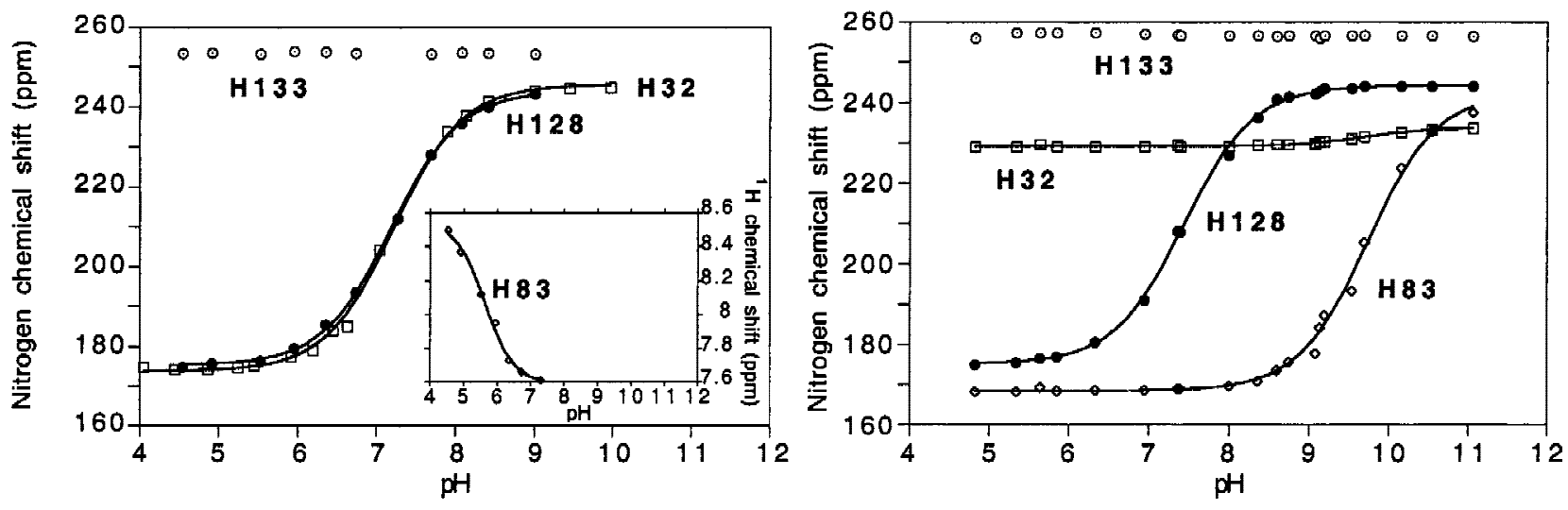

Fig. 2. Heme pocket histidine ${ }^{15} \mathrm{~N}$ chemical shifts of Has $\mathrm{A}_{\mathrm{SM}}$ for the apo-form (left) and for the holo-form (right) as a function of pH. The solid lines represent the least-squares best fit to the data. The titration curve for the His $83{ }^{1} \mathrm{H}$ resonance in the apo-Has $\mathrm{A}_{\mathrm{SM}}$ is shown in the bottom right corner because only partial ${ }^{15} \mathrm{~N}$ titration curves didn't allow to determine the pKa value by fitting the data for this residue. 
two imidazole rings are parallel to each other and separated by $\sim 4 \AA$.

His 128 has a neutral pKa in apo- and GaPPIX-HasA $\mathrm{A}_{\mathrm{SM}}$ (7.1 and 7.4, respectively). It predominantly adopts the $\mathrm{N} \varepsilon 2 \mathrm{H}$ tautomeric form in both apo-Has $\mathrm{A}_{\mathrm{SM}}$ and GaPPIXHas $_{\mathrm{SM}}$. These results are consistent with the interaction between His $128 \mathrm{~N} \varepsilon 2$ and Ala $82 \mathrm{CO}$ observed in the crystal structure, but the nitrogen chemical shift difference did not allow us to conclude about the formation of a hydrogen bond.

His 133 does not titrate over the $\mathrm{pH}$ range studied in apo-Has $_{\mathrm{SM}}(\mathrm{pH} 4$ to $\mathrm{pH} 10)$ or in GaPPIX-HasA $\mathrm{SM}_{\mathrm{SM}}(\mathrm{pH}$ 4.8 to $\mathrm{pH} 11$ ). The cross peak pattern and nitrogen chemical shifts clearly indicate that the residue is in the neutral state and adopts the $\mathrm{N} \varepsilon 2 \mathrm{H}$ tautomeric form. These data suggest that the side chain of His 133 forms a strong hydrogen bond and/or this residue is located in an environment that is particularly resistant to the protonation. It is likely that in both apo-Has $_{\mathrm{SM}}$ and GaPPIX-HasA $\mathrm{SM}_{\mathrm{SM}}$, His 133 is less accessible to solvent and is hydrogen bonded through its $\mathrm{N} \varepsilon 2 \mathrm{H}$ to the carbonyl group of His 83 .

GaPPIX binding induces moderate $(<1.5 \mathrm{ppm})$ downfield shifts of the proton chemical shifts of both His 128 and His 133 rings. These shifts reflect a weak protoporphyrin ring current effect, which is consistent with distances of over 7 $\AA$ between histidine ring and the metallic ion.

\section{His 17 and His 179}

According to the X-ray structure of holo-Has $\mathrm{A}_{\mathrm{SM}}$, His 17 belongs to helix $\alpha 2$. It is located at the interface between helix $\alpha 2$ and helix $\alpha 3$ and is highly exposed to solvents. Its $\mathrm{N} \delta 1$ is hydrogen bonded to the side chain carbonyl of Glu
148. His 179 is within the C-terminal region, which is shown to be highly flexible in a previous NMR study on apo-HasA $\mathrm{A}_{\mathrm{SM}}$ and belongs to the C-terminal 14 residues not observed in the X-ray structure (Izadi-Pruneyre et al. 1999b). As predicted by the distance of His 17 and His 179 from the binding site, the cross peak patterns and the $\mathrm{pKa}$ values of His 17 and His 179 are fairly unaffected by the GaPPIX binding. The spectra indicate the formation of predominant $\mathrm{N} \delta 1 \mathrm{H}$ and $\mathrm{N} \varepsilon 2 \mathrm{H}$ tautomers for His 17 and His 179, respectively. The predominance of the His $17 \mathrm{~N} \delta 1 \mathrm{H}$ tautomer supports the existence of the hydrogen bond observed in the crystal structure between its $\mathrm{H} \delta 1$ proton and Glu 148 side-chain carbonyl group, regardless of $\mathrm{pH}$. The basic pKa of imidazole is probably due to the stabilization of the protonated ring through this interaction. The $\mathrm{N} \varepsilon 2 \mathrm{H}$ tautomeric state of His 179 is more populated in the apoform of Has $\mathrm{A}_{\mathrm{SM}}$ and less populated in the GaPPIX complex than in free histidine, although no obvious hydrogen bonding account for these data.

\section{Conclusion}

The NMR data for the GaPPIX-HasA $\mathrm{AM}_{\mathrm{SM}}$ complex are consistent with the topology of the heme-binding pocket that was determined by X-ray diffraction (Fig. 3) and with our study on the heme binding of HasA $\mathrm{A}_{\mathrm{SM}}$ and its mutants. As shown by the cross-peak patterns and by the titration curves, GaPPIX binding has a major effect on the protonation state and the ring atom chemical shifts of the two histidines that are directly implicated in the heme-binding process: His 32 and His 83. Their tautomeric states change when GaPPIX binds and they show the largest differences in the pKa values between apo- and GaPPIX-HasA forms, resulting in

A

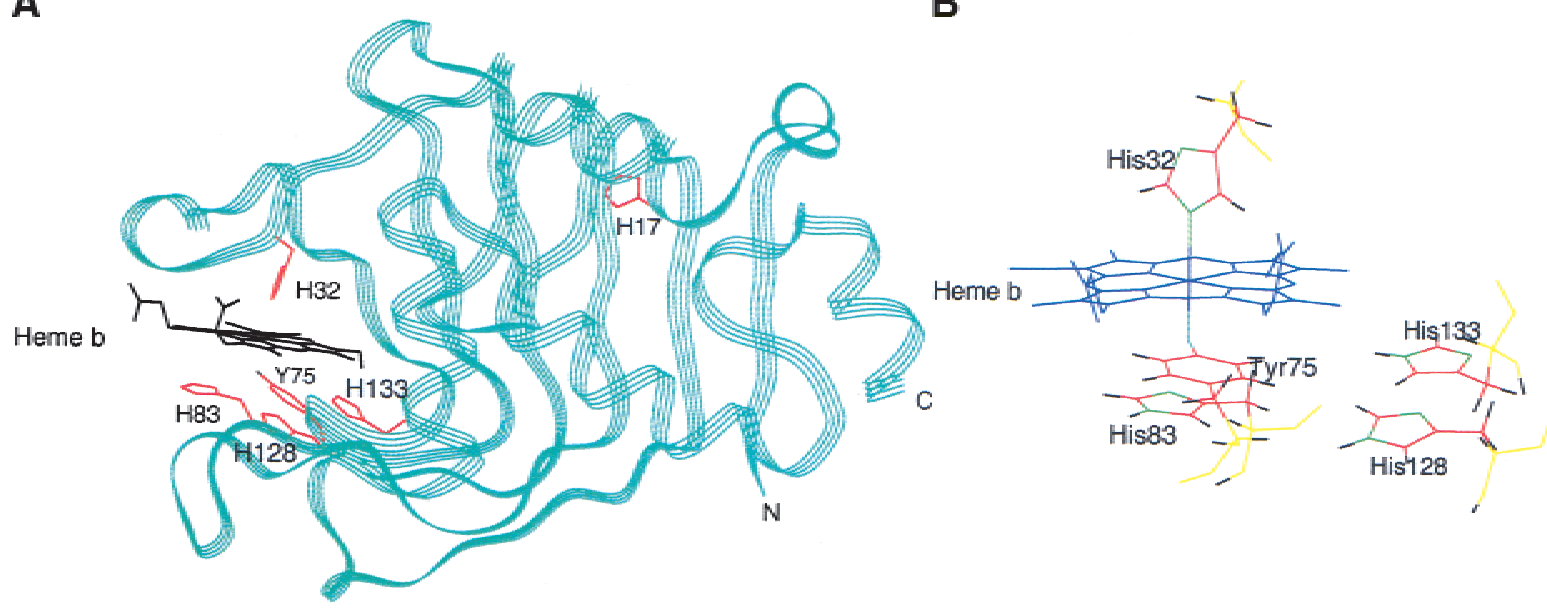

Fig. 3. (A) Ribbon representation of the overall HasA X-ray crystal structure with the location of $\mathrm{b}$ heme, histidines, and Tyr 75 residues (PDB entry 1B2V; Arnoux et al. 1999). (B) Detailed view of the b heme structural environment. Nitrogens are shown in green, oxygen in light blue, hydrogens in black, carbons in red, and backbone in yellow. 
distinct hydrogen bond networks. GaPPIX binding only has a minor effect on the four other histidines.

His 32 must be in a neutral state for heme or GaPPIX binding, because coordination occurs through its unprotonated nitrogen. According to its $\mathrm{pKa}$, His 32 is deprotonated in apo-Has $\mathrm{A}_{\mathrm{SM}}$ for $\mathrm{pH}$ values higher than 7.3 and predominantly adopts a $\mathrm{N} \varepsilon 2 \mathrm{H}$ tautomeric form. At these $\mathrm{pH}$, His 83 is also deprotonated $(\mathrm{pKa}=5.6)$ and can form a hydrogen bond via its $\mathrm{N} \delta 1$ with the phenolic proton $\mathrm{H} \eta$ of Tyr 75. As Has $_{\mathrm{SM}}$ binds heme, the tautomeric equilibrium of His 32 is displaced toward the formation of the $\mathrm{N} \delta 1$ tautomer, $\mathrm{N} \varepsilon 2$ coordinating to the metallic ion. His 83 is protonated $(\mathrm{pKa}=9.7)$ and can act as a hydrogen donor to form a hydrogen bond with the $\mathrm{O} \eta$ of Tyr 75 via its $\mathrm{N} \delta 1 \mathrm{H}$, thus enhancing the nucleophilic character of the phenolate and increasing the strength of the coordination to the metallic ion (Fig. 4). This result is consistent with our previous data on Has $\mathrm{A}_{\mathrm{SM}}$ mutant proteins showing that Tyr 75 is a stronger ligand than His 32 and, therefore, is in an unprotonated state (Létoffé et al. 2001). The study on the Tyr75Ala mutant apo-protein confirmed the direct influence of Tyr 75 on the His 83 protonation state. Our results strongly support that His 83 may control the protonation state of the Tyr 75 side chain. It is noteworthy that, unlike His 32, the couple Tyr 75/His 83 is conserved in the three other known hemophores: Pseudomonas fluorescens (Has $\mathrm{A}_{\mathrm{PF}}$ ), Pseudomonas aeruginosa (Has $\mathrm{A}_{\mathrm{PA}}$ ), and Yersinia pestis (Has $\left.\mathrm{A}_{\mathrm{YP}}\right)$. A hydrogen bond between Tyr 75 and His 83 was observed in the crystal structure of heme-Has $\mathrm{A}_{\mathrm{sm}}$ at $\mathrm{pH} 4.6$ without presuming of the hydrogen donor. We have shown here that His 83 is protonated up to $\mathrm{pH} 4.8$ and thus can act as the hydrogen donor. Tyr 75 is therefore deprotonated up to $\mathrm{pH}$ 4.8. The strong interaction between the negative tyrosinate ion and the positive imidazole could account for the very low pKa value of Tyr 75. Unusual acid stability of tyrosinate ion was already observed in other proteins. In ferric Chlamydomonas hemoglobin, it was proposed that the low $\mathrm{pKa}$ of the tyrosine ligand, about four units lower than that of free tyrosine, resulted from an interaction of the tyrosinate with a neighboring lysine (Das et al. 1999). Similarly, in UDP-galactose 4-Epimerase, a positive electrostatic field

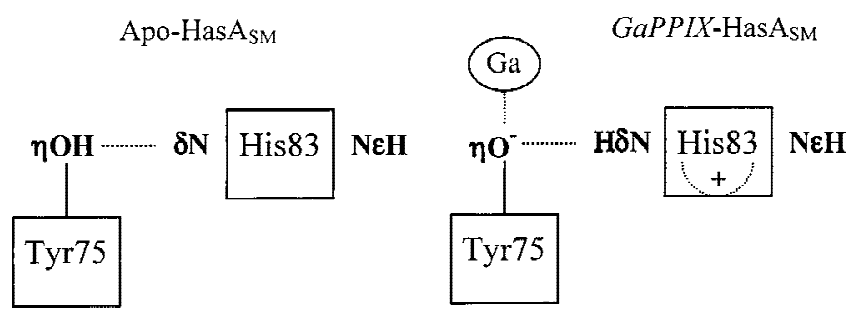

Fig. 4. Schematic representation of the Tyr 75-His 83 interaction in apo-

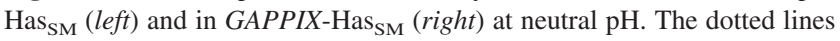
represent the hydrogen bond between the two residues. was proposed to strongly stabilize the phenolate form of a tyrosine in the active site (Liu et al. 1997).

Disruption of the metal coordination to His 32 by protonation of the imidazole needs an acidic $\mathrm{pH}$, because His $32 \mathrm{~N} \varepsilon 2$ still is deprotonated at $\mathrm{pH} 4.8$. The break of the metal coordination to Tyr 75 may occur via the protonation of the phenolate, which is controlled by His 83 at very basic $\mathrm{pH}$ values, His 83 remaining protonated up to 9.7. However, the release of heme involves a protein-protein interaction between Has $\mathrm{A}_{\mathrm{SM}}$ and its receptor $\mathrm{HasR}_{\mathrm{SM}}$, which probably induces conformational and dynamics changes, and variations in the heme environment. Analysis of the HasA $\mathrm{SM}^{-}$ HasR $_{\mathrm{SM}}$ complex, which is in progress in our laboratories, will allow us to complete the description of the heme release mechanism.

\section{Materials and methods}

\section{Expression and purification of the Has $A_{S M}$ proteins}

Wild-type Has $\mathrm{A}_{\mathrm{SM}}$ was expressed in Escherichia coli strain POP3 transformed with plasmid pSYC34 (pAM238) (Létoffé et al. 1994b). Mutant hasA genes were constructed by in vitro sitedirected mutagenesis (Létoffé et al. 2001). They were cloned in pAM238 and introduced into strain POP3 (pSYC15O) (Létoffé et al. 1994a). Uniformly labeled samples were produced in M9 minimal medium containing ${ }^{15} \mathrm{NH}_{4} \mathrm{Cl}$ as the sole nitrogen source, as reported previously (Izadi-Pruneyre et al. 1999a). Wild-type and mutant apo-Has $\mathrm{A}_{\mathrm{SM}}$ proteins (His32Ala, Tyr75Ala, His83Ala, His32Ala-Tyr75Ala) were purified as described previously (Izadi et al. 1997). Their heme content, determined from the absorbance of the Soret band wavelength, was always <.0.5\% .

\section{Absorption spectrometry and Ka determination}

Heme-binding experiments were carried out in $50 \mathrm{mM}$ sodium phosphate buffer ( $\mathrm{pH} \mathrm{7.3)}$ at room temperature by measuring the absorbance in the Soret region. Aliquots of GaPPIX solution (Adler et al. 1970) were successively added to the cell containing the apo-protein. Fresh GaPPIX solution was prepared immediately prior to the titration as follows: GaPPIX was dissolved in a minimal volume of $0.1 \mathrm{~N} \mathrm{NaOH}$ and diluted with phosphate buffer to the desired concentration using the $\varepsilon_{413}$, DMso value of 249000 $\mathrm{M}^{-1} \cdot \mathrm{cm}^{-1}$ (V. Kumar and I. Stojiljkovic, pers. comm.). Additional experimental details are given in reference Létoffé et al. (2001). The Soret band absorbance, $\mathrm{A}_{\text {Soret }}$, was measured with a base line drawn between 300 and $450 \mathrm{~nm}$ and reported as a function of the GaPPIX concentration in the cell. The curve was fitted using the kaleidaGraph 3.5 software and the Ka determined.

\section{NMR sample preparation}

When necessary, saturating amounts of gallium-protoporphyrin IX $(G a P P I X)$ solution were added to the apo-Has $\mathrm{A}_{\mathrm{SM}}$ wild-type and mutant proteins by following the absorbance in the Soret region. Samples were dialyzed against water, freeze dried, and dissolved in $20 \mathrm{mM}$ phosphate buffer, $99,97 \%{ }^{2} \mathrm{H}_{2} \mathrm{O}$ (pH 5.6). The concentrations of the wild-type and mutant proteins in both apo- and GaPPIX forms were $\sim 1$ and $0.3 \mathrm{mM}$, respectively. $\mathrm{pH}$ were ad- 
justed to the desired values with $0.1 \mathrm{M}^{2} \mathrm{HCl}$ or $\mathrm{NaO}^{2} \mathrm{H}$. pH were measured at room temperature before and after NMR data collection. The values were not corrected for the deuterium isotope effect.

\section{NMR spectroscopy}

NMR spectra were recorded at $30^{\circ} \mathrm{C}$ on a Varian Inova spectrometer operating at $500 \mathrm{MHz}$ for protons and equipped with a triple resonance z-gradient probe. Data processing was performed with standard Varian NMR software. ${ }^{1} \mathrm{H}\left\{{ }^{15} \mathrm{~N}\right\}$ SBC (Bodenhausen and Ruben 1980; Sklenar et al. 1994) and ${ }^{1} \mathrm{H}\left\{{ }^{15} \mathrm{~N}\right\} \mathrm{MBC}$ (Bax and Summer 1986) the 2D spectra were recorded for the wild-type and mutant proteins at each $\mathrm{pH}$ value. The delay for observation of the long-range proton-nitrogen correlation of histidine was $30 \mathrm{~ms}$ $\left(J_{\mathrm{N}-\mathrm{H}} \cdot \sim 15 \mathrm{~Hz}\right)$, which gave the best signal to noise ratio. Experimental parameters were as follows: ${ }^{1} \mathrm{H}$ and ${ }^{15} \mathrm{~N}$ sweep widths of $10000 \mathrm{~Hz}$ and $8500 \mathrm{~Hz}$, respectively, 64 and 512 complex $\mathrm{t}_{1}$ and $\mathrm{t}_{2}$ points, respectively, and 128 or 256 scans. Prior to Fourier transformation, each data set was zero filled to 512 and 2048 points in $\mathrm{F}_{1}$ and $\mathrm{F}_{2}$ dimensions, respectively, and the data were multiplied in both dimensions by a phase-shifted, skewed, sinebell window function. FIDs were Fourier transformed without baseline correction. Chemical shifts were measured relative to the external DSS for ${ }^{1} \mathrm{H}$ and calculated assuming $\gamma \mathrm{N} / \gamma \mathrm{H}=0.101329118$.

\section{pH titration and calculation of $p K a$}

NMR spectra were recorded at $20 \mathrm{pH}$ values between $\mathrm{pH} 4.0$ and $\mathrm{pH} 10.0$ for the wild-type apo-Has $\mathrm{A}_{\mathrm{SM}}$ and between $\mathrm{pH} 4.8$ and $\mathrm{pH} 11.0$ for the GaPPIX-HasA ${ }_{\mathrm{SM}}$. Experiments were performed at $10 \mathrm{pH}$ values between $\mathrm{pH} 4.9$ and $\mathrm{pH} 9.0$ for the apo-Tyr75Ala mutant. Proteins precipitated below $\mathrm{pH}$ 4.5.

The $\mathrm{pKa}$ values of the six Has $\mathrm{A}_{\mathrm{SM}}$ histidines were determined from the $\mathrm{pH}$ dependencies of their ${ }^{15} \mathrm{~N}$ and ${ }^{1} \mathrm{H}$ chemical shifts. The $\mathrm{pH}$ titration curves were fitted to a modified Henderson-Hasselbalch equation by nonlinear least-squares analysis:

$$
\delta_{o b s}=\frac{\delta_{A H^{+}}+\delta_{A} 10^{(p H-p K a)}}{1+10^{(p H-p K a)}}
$$

in which $\delta_{\text {obs }}$ is the chemical shift observed at each $\mathrm{pH}$ value and $\delta_{\mathrm{AH}+}$ and $\delta_{\mathrm{A}}$ are the chemical shifts for the protonated and deprotonated histidines, respectively. Curve fits were performed using the KaleidaGraph3.5 Software (Synergy Software).

\section{Structure analysis}

The X-ray holo-HasA structure (PDB filecode 1B2V, Arnoux et al. 1999) was analyzed. This allowed us to calculate the solvent accessibility of histidines and to check the hydrogen-bonding pattern involving these residues by use of Insight II Biosym/MSI.

\section{Acknowledgments}

We thank Drs Philippe Delepelaire and Laurent Debarbieux for fruitful discussions and for critical reading.

The publication costs of this article were defrayed in part by payment of page charges. This article must therefore be hereby marked "advertisement" in accordance with 18 USC section 1734 solely to indicate this fact.

\section{References}

Adler, A.D., Longo, F.R., Kampas, F., and Kim, J. 1970. Preparation of metalloporphyrins. J. Inorg. Nucl. Chem. 32: 2443.

Alam, S.L., Volkman, B.F., Markley, J.L., and Satterlee, J.D. 1998. Detailed NMR analysis of the heme-protein interactions in component IV Glycera dibranchiata monomeric hemoglobin-CO. J. Biomol. NMR 11: 119-133.

Arnoux, P., Haser, R., Izadi, N., Lecroisey, A., Delepierre, M., Wandersman, C., and Czjzek, M. 1999. The crystal structure of HasA, a hemophore secreted by Serratia marcescens. Nat. Struct. Biol. 6: 516-520.

Arnoux, P., Haser , R., Izadi-Pruneyre, N., Lecroisey, A., and Czjzek, M. 2000. Functional aspects of the heme bound hemophore HasA by structural analysis of various crystal forms. Proteins 41: 202-210.

Bax, A. and Summer, M. 1986. H-1 and C-13 assignments from sensitivityenhanced detection of heteronuclear multiple-bond connectivity by $2 \mathrm{D}$ multiple quantum NMR. J. Am. Chem. Soc. 108: 2093-2094.

Bhattacharya, S., Sukits, S., MacLaughlin, K., and Lecomte, J. 1997. The tautomeric state of histidine in myoglobin. Biophys. J. 73: 3230-3240.

Blomberg, F., Maurer, W., and Rüterjans, H. 1977. Nuclear magnetic resonance investigation of $15 \mathrm{~N}$-labeled histidine in aqueous solution. J. Am. Chem. Soc. 99: 8149-8159.

Bodenhausen, L. and Ruben, D.J. 1980. Natural abundance N-15 NMR by enhanced heteronuclear spectroscopy. Chem. Phys. Lett. 69: 185-189.

Braun, V. and Killmann, H. 1999. Bacterial solutions to the iron-supply problem. Trends Biochem Sci 24: 104-109.

Das, T.K., Couture, M., Lee, H.C., Peisach, J., Rousseau, D.L., Wittenberg, B.A., Wittenberg, J.B., and Guertin, M. 1999. Identification of the ligands to the ferric heme of Chlamydomonas chloroplast hemoglobin: Evidence for ligation of tyrosine-63 (B10) to the heme. Biochemistry 38: 15360-15368.

Deniau, C., Couprie, J., Simenel, C., Kumar, V., Stojiljkovic, I., Wandersman, C., Delepierre, M., and Lecroisey A. 2001. J. Biomol. NMR 21: 189-190.

Ghigo, J. M., Létoffé, S., and Wandersman, C. 1997. A new type of hemophoredependent heme acquisition system of Serratia marcescens reconstituted in Escherichia coli. J. Bacteriol. 179: 3572-3579.

Guiles, R.D., Altman, J., Kuntz, I.D., and Waskell, L. 1990. Structural studies of cytochrome b5: Complete sequence-specific resonance assignments for the trypsin-solubilized microsomal ferrocytochrome b5 obtained from pig and calf. Biochemistry 29: 1276-1289.

Izadi, N., Henry, Y., Haladjian, J., Goldberg, M. E., Wandersman, C., Delepierre, M., and Lecroisey, A. 1997. Purification and characterization of an extracellular heme-binding protein, HasA, involved in heme iron acquisition. Biochemistry 36: 7050-7057.

Izadi-Pruneyre, N., Wolff, N., Castagne, C., Czisch, M., Wandersman, C., Delepierre, M., and Lecroisey, A. 1999a. Backbone NMR assignment and secondary structure of the $19 \mathrm{kDa}$ hemophore HasA. J. Biomol. NMR 14: 193-194.

Izadi-Pruneyre, N., Wolff, N., Redeker, V., Wandersman, C., Delepierre, M., and Lecroisey, A. 1999b. NMR studies of the C-terminal secretion signal of the haem-binding protein, HasA. Eur. J. Biochem. 261: 562-568.

Létoffé, S., Ghigo, J.M., and Wandersman, C. 1994a. Secretion of the Serratia marcescens HasA protein by an ABC transporter. J. Bacteriol. 176: 5372 5377.

Létoffé, S., Ghigo, J.M., and Wandersman, C. 1994b. Iron acquisition from heme and hemoglobin by a Serratia marcescens extracellular protein. Proc. Natl. Acad. Sci. 91: 9876-9880.

Létoffé, S., Deniau, C., Wolff, N., Dassa, E., Delepelaire, P., Lecroisey, A., and Wandersman, C. 2001. Haemophore-mediated bacterial haem transport: Evidence for a common or overlapping site for haem-free and haem-loaded haemophore on its specific outer membrane receptor. Mol. Microbiol. 41: 439-450.

Liu Y., Thoden, J.B., Berger, E., Gulick, A.M., Ruzicka, F.J., Holden, H.M.., and Frey, P.A. 1997. Mechanistic roles of tyrosine 149 and serine 124 in UDP-galctose 4-epimerase from Escherichia coli. Biochemistry 36 : 10675 10684.

Martin, R.B. 1988. Bioinorganic chemistry of aluminium. Met. Ions Biol. Syst. 24: $1-57$.

Maurus, R., Bogumil, R., Luo, Y., Tang, H.L., Smith, M., Mauk, A.G., and Brayer, G.D. 1994. Structural characterization of heme ligation in the His64 $\rightarrow$ Tyr variant of myoglobin. J. Biol. Chem. 269: 12606-12610.

Nagai, M., Yoneyama, Y., and Kitagawa, T. 1989. Characteristics in tyrosine coordinations of four hemoglobins M probed by resonance Raman spectroscopy. Biochemistry 28: 2418-2422.

Nozaki, Y. and Tanford, C. 1967. Examination of titration behavior. Methods Enzymol. 11 : 715-734.

Pelton, J.G., Torchia, D A., Meadow, N.D., and Roseman, S. 1993. Tautomeric 
states of the active-site histidines of phosphorylated and unphosphorylated IIIGlc, a signal-transducing protein from Escherichia coli, using two-dimensional heteronuclear NMR techniques. Protein Sci. 2: 543-558.

Rousseau, D.G. and Rousseau, D.L. 1992. Hydrogen bonding of iron-coordinated histidine in heme proteins. J. Struct. Biol. 109: 13-17.

Sklenar, V., Peterson, R.D., Rejante, M.R., and Feigon, J. 1994. Correlation of nucleotide base and sugar protons in a 15N-labeled HIV-1 RNA oligonucleotide by $1 \mathrm{H}-15 \mathrm{~N}$ HSQC experiments. J. Biomol. NMR 4: 117-122.

Steensma, E., Gordon, E., Öster, L., Ferguson, S.J., and Hajdu, J. 2001. Heme ligation and conformational plasticity in the isolated c domain of cytochrome cd1 nitrite reductase. J. Biol. Chem. 276: 5846-5855.

Stojiljkovic, I., Kumar, V., and Srinivasan, N. 1999. Non-iron metalloporphyrins: Potent antibacterial compounds that exploit haem/Hb uptake systems of pathogenic bacteria. Mol. Microbiol. 31: 429-442.
Tanokura, M. 1983. 1H-NMR study on the tautomerism of the imidazole ring of histidine residues. I. Microscopic pK values and molar ratios of tautomers in histidine-containing peptides.Biochim. Biophys. Acta 742: 576-585.

Van Dijk, A.A., Scheek, R.M., Dijkstra, K., Wolters, G.K., and Robillard, G.T. 1992. Characterization of the protonation and hydrogen bonding state of the histidine residues in IIAmtl, a domain of the phosphoenolpyruvate-dependent mannitol-specific transport protein. Biochemistry 31: 9063-9072.

Yamamoto, Y., Nakashima, T., Kawano, E., and Chûjô, R. 1998. 1H-NMR investigation of the influence of the heme orientation on functional properties of myoglobin. Biochim. Biophys. Acta 1388: 349-362.

Yu, L.P. and Smith, G.M. 1990. Characterization of pH-dependent conformational heterogeneity in Rhodospirillum rubrum cytochrome c2 using $15 \mathrm{~N}$ and 1H NMR. Biochemistry 29: 2920-2925. 